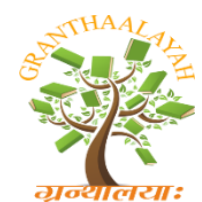

INTERNATIONAL JOURNAL OF RESEARCH GRANTHAALAYAH A knowledge Repository

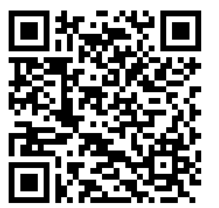

Social

\title{
A SURVEY OF VOCABULARY USED IN ONLINE FOOD RECIPE WEBSITES
}

\author{
Sommai Bunsaeng ${ }^{* 1}$, Nutprapha K. Dennis ${ }^{2}$ \\ ${ }^{* 1,2}$ English Department, Graduate School, Ubon Ratchathani Rajabhat University, Thailand
}

DOI: https://doi.org/10.29121/granthaalayah.v5.i1.2017.1695

\begin{abstract}
The purpose of this study was to survey vocabulary used in online Thai food recipes from two websites www.BBCGoodFood.com and www.ThaiTable.com. The ten selected recipes analyzed in this study were only from the Thai main course recipes category. The vocabulary used is categorized into 8 categories as parts of speech; noun, pronoun, verb, adverb, adjective, preposition, conjunction, and determiner. The results of the study showed that there were 1,468 words with 8 types of parts of speech. The results revealed that in the ten recipes it used nouns the most with 372 words $(37.2 \%)$ and least is pronoun with 10 words $(0.7 \%)$. Results of the study showed that learners can study many different kinds of words. The learner can analyze the function and kind of the word that is in the instruction; the base form of part of speech is helpful for making instruction in the recipe writing.
\end{abstract}

Keywords: Thai Food Recipe; Online Thai Food Recipe Website; Type of Words.

Cite This Article: Sommai Bunsaeng, and Nutprapha K. Dennis. (2017). "A SURVEY OF VOCABULARY USED IN ONLINE FOOD RECIPE WEBSITES." International Journal of Research - Granthaalayah, 5(1), 90-98. 10.29121/granthaalayah.v5.11.2017.1695.

\section{Introduction}

At present, English has become an international language that is widely used around the world. It plays a dominant role as a first, second or foreign language in many countries. In addition, there is an increasing demand for using English as a foreign language in several countries. Nowadays, there are approximately over two billion people in the world speaking English, with varying degrees of fluency.

According to the resource, in present global education, online English websites enable students to assimilate many aspects of the English language, especially everyday English. Learning English through online English websites also assists one to practice English by listening, speaking, reading and writing. Benson (1985) explains that the website is important to organizations and is recognized by all Industries including educational organizations and 
institutions. The main benefit of English learning websites is that millions of students can be reached.

BBC Good Food Website and Thai Recipes - ThaiTable Website can help EFL students to understand English through recipes, because they use appropriate vocabulary at students' level which they can choose to study, to improve the use of the English language. The learner can also study many different kinds of words, for example nouns, verbs, adjectives, and adverbs. The learner can analyze the function and kind of the word that is in the instruction. Learners often consider that it is a simple thing and it is not important to the learner. As an English teacher, look at the meaning of the text and ignore or neglect the function and kind of the words. Whereas, kinds of word are important components in English learning because those are very useful for us when we express our utterances or write English sentences. Therefore, this study surveyed vocabulary used in the recipe for the benefit of students who learn English as a foreign language.

Nation (1990) defines collocation as the tendency of two or more words to co-occur in discourse. There are two basic types of collocations: semantic collocations and grammatical collocations (Benson, 1985). Semantic collocations mean that the type consists of two equal words both with meaning to produce a new meaning, e.g. air balloon. The other ones refer to the type in which a core word goes with a functional word, e.g. in devote to, devote is the core word, and to is the functional word having no meaning.

Concerning the grammatical behavior, it means the pattern in which it typically occurs. Two of the most important aspects of lexis are word class and morphology. There are four major parts in word class: noun, verb, adjective and adverb. Morphology involves affixes including prefix such as un- and suffix such as -ment. The morphology is also about how these affixes are attached to the basic forms of words (Laufer, 1997).

On the aspect of form of a word, Nation (1990) states there are two kinds of a word form. They are written form and spoken form. The written form of a word refers to the spelling and the spoken form means the sound or pronunciation. The last aspect is always referring to how often any particular word occurs in usage. According to the above aspects of a word, both teachers and learners should hold a broad view of mastering a word and adopt different strategies to gain a full command of a word.

Chumchai (2008) had done research related to vocabulary learning. The purpose of this research was to analyze how linguistic features work (i.e. lexical expansion, semantic features and language functions) in Korean movie synopses. Quotes from 30 movie synopses were selected and analyzed based on theories of linguistic features. The current study showed that the linguistic features were used in diverse ways in movie synopses. In the current study, 15 expressions of linguistic features were revealed. Three types of linguistic features were used more frequently than others: lexical expansion, semantic features and language functions.

Poompuang (2005), this study is focused on the English usage in perfume advertising from a particular web page. The purpose of the study was to examine the linguistics features used in perfume advertising. The data analyzed in this study were 30-perfume advertisements randomly selected from web pages. This study was designed as a qualitative research, as analysis of the 
data in the frame of persuasive language, figurative language and word formation. The results reveal that there are styles of linguistics features used in the collected data. Most perfume advertisements implemented persuasive messages and more than half of the advertisements contained figurative language forms, which were more than three quarters of the word formation.

Cahyani (2012) had done a related research which the purpose of the article is to analyze the types of adjectives and adjective functions in a noun phrase found in an online news site "The Jakarta Globe". Online news sites are very well known in all circles, both among young people and adults, because the news is very easy to access. The information and latest news provided by the online news website can be published in a very quick time, without waiting for a longer period of time; just a few minutes are enough to gain all information for the interested users. This study uses the qualitative method, as well as the best possible literature method. The theory which is used as a reference in this research is a theory about the types of adjectives by A. J. Thomson and A.V. Martinet in their book with the title: "A Practical English Grammar Use", plus the theory of functions of word properties by Quirk in his book with the title: A Comprehensive Grammar of the English Language. The results of this study indicate that there are six types of adjectives in the British language: demonstrative adjectives, distributive adjectives, quantitative adjectives, interrogative adjectives, possessive adjectives, and adjectives of quality, as well as three function words properties in a noun phrase: attributive functions, postpositive functions, and adjectives as "the head of the noun phrase".

From researching the document and the studies above, the researcher is interested in using online websites to develop the English learning ability of primary school students in an effective way.

One of the studies that have attempted to investigate which vocabulary strategies are most commonly used has revealed that more mechanical strategies are often favored over more complex ones. In an experiment, O'Malley (1990) had found that repetition was the most commonly mentioned strategy, with strategies involving deeper, more involved manipulation of information (i.e. imagery, inferencing, Keyword Method) being much less frequent. Another vocabulary learning strategy research has attempted to identify the ways in which "good" and "poor" learners move toward lexical learning.

\subsection{Purpose of the Study}

The purpose of this study was to survey vocabulary used in online Thai food recipes from two websites www.BBCGoodFood.com and www.ThaiTable.com.

\subsection{Scope of the Study}

This research focused on studying part of speech used or Thai food recipe from two websites only. They are http://www.BBCGoodFood.com and http://www. ThaiTable.com. The ten selected recipes analyzed in this study are only Thai main course recipes category. The vocabulary used was divided into 8 categories as parts of speech; noun, pronoun, verb, adverb, adjective, preposition, conjunction, and determiner. 


\subsection{Significance of the Study}

This study will help English learner to learn parts of speech through Thai food recipes by reading and following the recipes' instructions. In addition, it helped to identify parts of speech used in Thai food recipes as well. This study might be beneficial for interested people or other language learners, educational institutions and practitioners to develop the use of English vocabulary.

\section{Materials and Methods}

The setting of this study was based on ten Thai main course recipes from the website http://www.BBCgoodfood.com and http://www.ThaiTable.com.

In this study, ten recipes were analyzed. The selected recipes were from www.BBCgood food.com and www.Thaitable.com. The selected sections for this study were name of the recipes, ingredients, and methods of cooking, as follows: Pad Thai, Green Beans and Shrimp, Thai Chicken and Sweet Potato Soup, Tom Yum (hot \& sour) Soup with Prawns, Thai Pork \& Peanut Curry, Thai Fried Rice with Prawns \& Peas, Thai Prawn, Ginger \& Spring Onion Stir Fried, Thai Beef Stir Fried, Thai Shredded Chicken \& Runner Bean Salad, Ken Hom's Stir Fried Chicken with Chilies \& Basil Recipe.

\subsection{Data Collection and Analysis}

Ten Thai main course recipes from BBCGoodFood.com and ThaiTable.com were analyzed. Forty Thai recipes were collected from the selected website. The recipes selected in this study contain the recommended word count.

The instrument used in this study was a checklist which determined and categorized parts of speech. According to the information that the good recipes should be concise and not too long but easy to understand and follow. The recipe with 300-500 words is a good length, which is randomly calculated from the online recipes.

The data was analyzed as follows: first, the researcher searched the BBC GoodFood.com and Thai Recipe - ThaiTable of recipes to choose recipes. Second, ten recipes were randomly selected from main course category. Third, words were categorized in each recipe into part of speech group. Fourth, the researcher examined the part of speech in order to understand how a part of speech was used to represent recipes. Fifth, content analysis was used to analyze the number and type of part of speech used in recipes in order to examine how a part of speech was used to represent recipes. Sixth, the researcher found the frequency and the number of different part of speech, and presented the results in the form of a table. Last, the researcher wrote a final report.

\section{Results and Discussions}

The analysis of the ten Thai main course recipes is summarized and presented by percentage and frequency of part of speech. 


\section{"Pad Thai Recipe"}

The analysis of percentage and frequency of part of speech from 142 words identified from a Thai food recipe, 'Pad Thai'. The results show the percentage and frequency of part of speech from the recipe, 'Pad Thai'. Part of speech used the most is nouns with 55 words (39\%); for example, ingredients, pack, rice, noodles, lime, cayenne, pepper, etc. Prepositions and determiners were used 18 times (13\%); for example, of, in, over, for, a, the, etc. There were 17 words $(12 \%)$ that are verbs in the recipe; for example, chopped, put, pour, boiling, leave, etc. Adjective usage totaled 16 words (11\%); for example, ready, large, sweet, small, large, etc. Twelve of the words were conjunctions (8\%); it was 'and' (showed 12 times). There were 5 words (4\%) from adverb in this recipe; for example, finely, then, well, around, etc. Words from part of speech used the least are pronoun with 1 word (1\%); it was 'them'.

\section{"Green Beans and Shrimp Recipe"}

The analysis of percentage and frequency of part of speech from 68 words identified from a Thai food recipe, "Green Beans and Shrimp recipe". The results show the percentage and frequency of part of speech from the recipe, "Green Beans and Shrimp recipe". The part of speech used the most is noun with 31 words (46\%); for example, beans, cup, shrimp, teaspoons, sugar, etc. Verb was used 12 times (18\%); for example, curry, add, pan, stir, break, add, etc. There were 8 words (12\%) from Preposition in the recipe; for example, of, in, over, for, on, etc. chopped, put, pour, boiling, leave, Adjective and Conjunction were used 6 times (9\%); for example, ready, large, sweet, small, large, and, or, etc. Determiner was used 3 times (4\%); it was 'the'. Part of speech used the least is pronoun with 1 word (1\%); it was 'quickly' and 'it'.

\section{"Thai Chicken and Sweet Potato Soup Recipe"}

The analysis of percentage and frequency of part of speech from 171 words identified from a Thai food recipe, 'Thai chicken and sweet potato soup recipe'. The results show the percentage and frequency of part of speech from the recipe, 'Thai chicken and sweet potato soup recipe'. Words from part of speech used the most is nouns with 80 words $(47 \%)$; for example, root, chicken, fish, ingredients, pack, rice, noodles, etc. There were 31 words $(18 \%)$ from verb in the recipe; for example, add, peeled, sliced, chopped, put, leave, etc. Determiner was used 16 words (9\%); for example, the, a, etc. Preposition and adjective was used 13 times (8\%); for example, of, in, over, for, green, red, large, sweet etc. Conjunction was used 12 times (7\%); it was 'and' and 'or'. There were 6 words (4\%) that are an adverb in this recipe; for example, finely, then, well, separately, roughly, gently, etc. Pronoun was the part of speech that was not used.

\section{"Tom Yum (hot \& sour) Soup with Prawns Recipe"}

The analysis of percentage and frequency of part of speech from 90 words identified from a Thai food recipe, 'Tom yum (hot \& sour) soup with prawns recipe'. The results show the percentage and frequency of part of speech from the recipe, 'Tom yum (hot \& sour) soup with prawns' recipe'. Part of speech used the most is nouns with 29 words (32\%); for example, ingredients, pack, rice, noodles, lime, cayenne, pepper, etc. Adjective was used 23 times (26\%); for example, ready, large, sweet, small, large, etc. There were 15 words (17\%) that are a verb in the recipe; for example, chopped, put, pour, boiling, leave, etc. Preposition was used 18 times (13\%); for example, of, in, over, for, a, the, etc. There were 7 words (8\%) from determiner in this recipe; it was 'the' and 'a'. Conjunction and adverb was used 5 words (6\%); for example, finely, then, well, around, etc. Pronoun was the part of speech that was not used. 


\section{"Thai Pork \& Peanut Curry Recipe"}

The analysis of percentage and frequency of part of speech from 169 words identified from a Thai food recipe, 'Thai pork \& peanut curry recipe'. The results show the percentage and frequency of part of speech from the recipe, 'Thai pork \& peanut curry recipe'. Words from part of speech used the most are nouns with 55 words (33\%); for example, soy, coconut, milk, pack, rice, lime, pepper, etc. There were 48 words (28\%) from verb in the recipe; for example, chopped, put, pour, boiling, leave, etc. Preposition was used 20 times (12\%); for example, of, in, over, for, etc. There were 18 words (11\%) from determiner in this recipe; it were 'and' (showed 13 times) and 'or' (showed 1 time).Conjunction was used 14 times (8\%) the words were 'the' and 'or'. Adjective was used 8 times (5\%); for example, ready, large, sweet, small, red, etc. There were 6 words (4\%) from adverb in this recipe; for example, finely, then, well, occasionally, etc. Pronoun was the part of speech that was not used.

\section{"Thai Fried Rice with Prawns \& Peas Recipe"}

The analysis of percentage and frequency of part of speech from 146 words identified from a Thai food recipe, 'Thai fried rice with prawns \& peas recipe'. The results show the percentage and frequency of part of speech from the recipe, 'Thai fried rice with prawns \& peas recipe'. Words from part of speech used the most is nouns with 40 words (27\%); for example, ingredients, pack, rice, noodles, lime, cayenne, pepper, etc. There were 36 words (25\%) from verb in the recipe; for example, chopped, serve, used, pour, boiling, leave, etc. Preposition was used 26 times (18\%); for example, of, in, over, for, etc. Adjective was used 20 times (14\%); for example, ready, large, sweet, small, large, etc. Conjunction was used 10 times (7\%); the word was 'and' (showed 10 times). There were 8 words (5\%) from determiner in this recipe; they were ' $a$ ' and 'the'. Pronouns and adverb was used 3 times (2\%); for example, 'you' (showed 2 times) and 'we' (showed 1time).

\section{"Thai Prawn, Ginger \& Spring Onion Stir Fried Recipe"}

The analysis of percentage and frequency of part of speech from 232 words identified from a Thai food recipe, 'Thai prawn, ginger \& spring onion stir-fry recipe'. The results show the percentage and frequency of part of speech from the recipe, 'Thai prawn, ginger \& spring onion stir-fry recipe'. Words from part of speech used the most is nouns with 86 words (37\%); for example, ingredients, pack, rice, noodles, lime, cayenne, pepper, etc. There were 41 words (18\%) from verb in the recipe; for example, chopped, put, pour, boiling, leave, etc. Determiner was used 29 times (13\%); for example, these, this, the, a. Preposition was used 26 times (11\%); for example, of, in, over, for, a, the, etc. Conjunction was used 16 times (7\%); the words were 'and' (showed 14 times) and 'or' (showed 2 times). There were 13 words (6\%) from adverb in this recipe; for example, finely, then, well, around, etc. Part of speech used the least is pronoun with 3 words (1\%); they were 'them', 'their', 'they'.

\section{"Thai Beef Stir Fried Recipe"}

The analysis of percentage and frequency of part of speech from 93 words identified from a Thai food recipe, 'Thai beef stir-fry recipe'. The results show the percentage and frequency of part of speech from the recipe, 'Thai beef stir-fry recipe'. Words from part of speech used the most is nouns with 38 words (41\%); for example, beef, meat, rice, sauce, lime, pan, oil, etc. Preposition and verb was used 12 times (13\%); for example, of, in, over, for, put, pour, boiling, leave, etc. There were 11 words (12\%) from determiner in the recipe; it was 'a' and 'the'. Adjective was 
used 9 times (10\%); for example, ready, large, sweet, small, large, etc. Conjunction was used 7 times (8\%); the words were 'and' (showed 12 times) and 'or' (showed 2 times). There were 4 words (4\%) from adverb in this recipe; for example, finely, then, well, around, etc. Pronoun was the part of speech that was not used.

\section{"Thai Shredded Chicken \& Runner Bean Salad Recipe"}

The analysis of percentage and frequency of part of speech from 208 words identified from a Thai food recipe, 'Thai shredded chicken \& runner bean salad recipe'. The results show the percentage and frequency of part of speech from the recipe, 'Thai shredded chicken \& runner bean salad recipe'. Part of speech used the most is nouns with 76 words (38\%); for example, sugar, potato, garlic, bean, water, etc. Determiner was used 40 times (19\%); for example, any, a, the, etc. There were 33 words (16\%) from verb in the recipe; for example, chopped, put, pour, boiling, leave, etc. Conjunction was used 18 times (9\%); the words were 'and' (showed 14 times), 'or' (showed 5 times) and 'but' (showed 1 time). Adjective was used 13 times (6\%); for example, red, green, sweet, small, large, etc. There were 6 words (3\%) from adverb in this recipe; for example, finely, then, together, still, etc. Part of speech used the least is pronoun with 1 words ( $1 \%)$; it was 'your'.

\section{"Ken Hom's Stir Fried Chicken with Chilies \& Basil Recipe"}

The analysis of percentage and frequency of part of speech from 149 words identified from a Thai food recipe, 'Ken Hom's stir-fried chicken with chilies \& basil recipe'. The results show the percentage and frequency of part of speech from the recipe, 'Ken Hom's stir-fried chicken with chilies \& basil recipe'. Part of speech used the most is nouns with 47 words (32\%); for example, chilies, chicken, rice, basil, oil, garlic, etc. There were 25 words (17\%) from verb in the recipe; for example, cut, put, pour, add, set, etc. Adjective was used 24 times (6\%); for example, hot, high, green, small, large, etc. Determiner was used 19 times (13\%); the words were 'the' (showed 12 times), 'all' (showed 1 time) and 'a' (showed 6 times). Preposition was used 14 times $(9 \%)$; for example, of, in, over, for, from, etc. Conjunction was used 11 times (7\%); the words were 'and' (showed 7 times) and 'or' (showed 4 times). There were 8 words (5\%) from adverb in this recipe; for example, very, then, coarsely, once, etc. Part of speech used the least is pronoun with 1 word $(1 \%)$; it was 'it'

All of the ten selected online Thai food recipes from an online BBC Good Food website and Thai Recipe - ThaiTable website, there were a combined 1,468 words which included 8 parts of speech. The researcher found that nouns were the most used part of speech in every recipe.

Of all the parts of speech, nouns are perhaps the most important. A noun is a word that identifies a person, animal, place, thing, or idea. Here, we'll take a closer look at what makes a noun a noun, and we'll provide some noun examples, along with some advice for using nouns in your sentences. Every language has words that are nouns. As you read the following explanations, think about some words that might fit into each category.

In contrast to function words, content words, or lexical words (including nouns, verbs, adjectives, and most adverbs), are words that carry the content or the meaning of a sentence. They are open-class words. Open classes accept the addition of new morphemes (words), through such processes as compounding, derivation, inflection, coining, and borrowing. 
In conclusion, in BBC Good Food and Thai Recipe - ThaiTable used the frequency and percentage of part of speech from the recipe. Part of speech used the most is nouns with 372 words $(37.2 \%)$ and the part of speech used the least is pronoun with 10 words $(0.7 \%)$. Because BBC Good Food Website and Thai Recipes - ThaiTable Website are both of main media that help students to understand recipes and information, because they are easy, activities and levels for the students, which they can choose to study, to improve the use of the English language. The learner can also study many different kinds of words. The learner can analyze the function and kind of the word that is in the instruction, the base from of part of speech helpful instruction for users on the site are extremely seem to be a good indication of thoughtful.

\section{Conclusions \& Recommendations}

The purpose of this study is to survey vocabulary used in online Thai food recipes from two websites www.BBCGoodFood.com and www.ThaiTable.com. The ten selected recipes analyzed in this study are only Thai main course recipes category. The vocabulary used was categorized into 8 parts of speech; noun, pronoun, verb, adverb, adjective, preposition, conjunction, and determiner. The results of the study showed that there were 1,468 words which included 8 parts of speech. The results revealed that in the recipes used nouns the most in the ten recipes with 372 words $(37.2 \%)$. Part of speech used the least is pronoun with 10 words $(0.7 \%)$. Results of the study showed that learners can study many different kinds of words. The learner can analyze the function and kind of the word that is in the instruction; the base form of part of speech is helpful for making instruction in the recipe writing.

Based on the results, some implications can be observed. First of all, an advantage of this study is that it will increase the public awareness on the importance of vocabulary learning strategies in second language learning and teaching. As mentioned in Oxford Dictionary vocabulary is not explicitly taught in most language classes. The findings in this study are benefits to readers, other researchers and learners who are interested in English language. They can, through these activities. Understand and use parts of speech to save time planning and saving money for learning English language through Thai food recipes in "BBC Good Food and Thai Recipe ThaiTable".

\subsection{Recommendation for Present Study}

The results of the current study can assist language teachers to improve their teaching methods. Second, teachers who are interested in their students' performance in learn the English vocabulary can introduce the vocabulary learning by using online Thai food recipe can easily use this case study as their teaching resource to enhance learners' educational outcome intensively and techniques to their students by designing useful tasks and giving relevant assignments. Third, other materials such as movies, songs, tales, newspapers, advertisements, etc. should be considered to study as well.

\subsection{Recommendation for Further Study}

Future studies on vocabulary learning strategies can be carried out from two viewpoints. 
- A further study of the vocabulary can be conducted on different types of recipe, for example, appetizer recipes, Soup recipes, snack, bakery recipes, etc.

- This case study conducted based on an online Thai food recipe, it would be interesting if the study conducted in other websites or other international food recipes from various of forms of language use.

- Other characteristics of language used in the recipe, for example, the sentence types, the participles, and the types of words used can be promising area of further research\

\section{Acknowledgements}

I would like to acknowledge the support of my adviser, Nutprapha Kongphet Dennis, Ph.D. She has helped me in suggestion and checking information and contents of my research paper. This term paper would not have been completed without her useful comments. My grateful thanks also go to Assistant Professor Wutti Leenam of the instructors at the Faculty of Humanities and Social Sciences of Ubon Ratchathani Rajabhat University and Naruemon Duangsang, Ph.D, the external examiner. Moreover, I would like personally thank my family and my friends for their love and encouragement.

\section{References}

[1] Benson, M. (1985). Collocations and Idioms. In R, Ilson (Ed.), Dictionaries, Lexicography and Language Learning. Oxford: Pergamon.

[2] Cahyani, N. W. M. (2012). Analysis of adjectives in noun phrase in online newspaper, The Jakarta Globe". English Department Faculty of Letters Udayana University.

[3] Chumchai, C. (2008). An Analysis of Linguistic Features in Selected Korean Movie Synopses. Master's Thesis. Chiangrai Rajabhat University.

[4] Laufer, B. (1997). Vocabulary: Description, Acquisition, and Pedagogy. Cambridge: Cambridge University Press.

[5] Nation, I. S. P. (1990). Teaching and learning vocabulary. Boston, Mass. Heinle \& Heine Publishers.

[6] O’Mally, J. M. (1990). Learning Strategies in Second Language Acquistition. Cambridge: Cambridge University Press.

[7] Poompuang, K. (2005). English Usage in Perfume Advertising from the Web Page: A Case Study. English for Business and Industry King Mongkut's Institute of Technology North Bangkok Academic Year.

\footnotetext{
*Corresponding author.

E-mail address: nootprapa@gmail.com
} 